\title{
ORIGINAL ARTICLE \\ Precision of dual-energy X-ray absorptiometry of the knee and heel: methodology and implications for research to reduce bone mineral loss after spinal cord injury
}

\author{
WT Peppler ${ }^{1}$, WJ Kim², K Ethans ${ }^{3}$ and KC Cowley ${ }^{4}$
}

Study design: Methodological validation of dual-energy $x$-ray absorptiometry (DXA)-based measures of leg bone mineral density (BMD) based on the guidelines of the International Society for Clinical Densitometry.

Objectives: The primary objective of this study was to determine the precision of BMD estimates at the knee and heel using the manufacturer provided DXA acquisition algorithm. The secondary objective was to determine the smallest change in DXA-based measurement of BMD that should be surpassed (least significant change (LSC)) before suggesting that a biological change has occurred in the distal femur, proximal tibia and calcaneus.

Setting: Academic Research Centre, Canada.

Methods: Ten people with motor-complete $\mathrm{SCl}$ of at least 2 years duration and 10 people from the general population volunteered to have four DXA-based measurements taken of their femur, tibia and calcaneus. BMDs for seven regions of interest (RIs) were calculated, as were short-term precision (root-mean-square (RMS) standard deviation $\left(\mathrm{g} \mathrm{cm}^{-2}\right)$, RMS-coefficient of variation (RMS-CV, \%)) and LSC. Results: Overall, RMS-CV values were similar between SCI $(3.63-10.20 \%$, mean $=5.3 \%)$ and able-bodied $(1.85-5.73 \%$, mean $=4 \%$ ) cohorts, despite lower absolute BMD values at each RIs in those with SCI (35\%, heel to $54 \%$, knee; $P<0.0001)$. Precision was highest at the calcaneus and lowest at the femur. Except at the femur, RMS-CV values were under 6\%.

Conclusions: For DXA-based estimates of BMD at the distal femur, proximal tibia and calcaneus, these precision values suggest that LSC values $>10 \%$ are needed to detect differences between treated and untreated groups in studies aimed at reducing bone mineral loss after $\mathrm{SCl}$.

Spinal Cord (2017) 55, 483-488; doi:10.1038/sc.2016.170; published online 20 December 2016

\section{INTRODUCTION}

Bone mineral loss and increased risk of leg fracture is currently an inevitable consequence of motor-complete spinal cord injury (SCI) (reviewed in Qin et al. ${ }^{1}$ and Biering-Sorensen et al. ${ }^{2}$ ). Retrospective analyses show fracture incidences from $2 \%$ to $>3 \%$ per year, with prevalence ranging from $19 \%$ to $34 \% \cdot{ }^{3-6}$ Given the health and social costs of treating leg fractures after SCI, identifying treatments that reduce or treat SCI-induced osteoporosis is an important clinical goal.

Although there is no currently accepted treatment for SCI-induced bone mineral loss, some activity-based treatments show promise. These include electrical stimulation-based therapies alone, ${ }^{7}$ or combined with passive standing in a frame $e^{8}$ or even passive standing alone, when performed at least $5 \mathrm{~h}$ weekly. ${ }^{9,10}$ The particular mode, dose and intensity of effective activity-based therapy needed to prevent or treat SCI-related bone loss remains to be determined.

To identify treatments that reduce SCI-related osteoporosis, a clinical tool that can reliably be used to detect changes in bone mineral at relevant sites is required. Dual-energy $\mathrm{X}$-ray absorptiometry (DXA) is the most commonly used diagnostic tool for identifying reduced bone mineral content in at-risk postmenopausal women. ${ }^{11}$ There are well-developed guidelines published by the International Society for Clinical Densitometry (ISCD) for the maximum acceptable difference in bone mineral density (BMD) between repeat scans at the hip and femur in the absence of biological change. Thus ISCD guidelines $^{12}$ indicate acceptable precision to be $1.9 \%$ at the lumbar spine (least significant change (LSC) $=5.3 \%$ ) and $2.5 \%$ at the femoral neck $(\mathrm{LSC}=6.9 \%)$, although lower, more precise values are not uncommon at centers investigating BMD in the general population. However, after SCI, the hip and spine do not show the greatest losses of BMD. Spine BMD is often normal and the proximal femur only slightly reduced, ${ }^{13}$ whereas more distal leg sites, such as the knee ${ }^{13}$ and heel ${ }^{14}$ demonstrate the greatest reductions in BMD after injury. Precision standards for the sites relevant to those with SCI that undergo the greatest BMD loss, such as at the $\mathrm{knee}^{13}$ or heel ${ }^{14}$ have yet to be developed.

Of all the bones in the body, the calcaneus has the highest proportion of trabecular bone $\left(>95 \%\right.$; Bonnick $\left.{ }^{11}\right)$. Since the calcaneus is a weight-bearing bone, if directly exposed to mechanical

${ }^{1}$ Faculty of Kinesiology and Recreation Management, University of Manitoba, Winnipeg, MB, Canada; ${ }^{2}$ Faculty of Science, University of Manitoba, Winnipeg, MB, Canada; ${ }^{3}$ Section of Physical Medicine and Rehabilitation, Department of Medicine and Rehabilitation, Department of Medicine, Faculty of Health Sciences, University of Manitoba, Winnipeg, MB, Canada and ${ }^{4}$ Department of Physiology and Pathophysiology, Faculty of Health Sciences, University of Manitoba, Winnipeg, MB, Canada

Correspondence: Dr KC Cowley, Department of Physiology and Pathophysiology, Faculty of Health Sciences, University of Manitoba, 405 Basic Medical Sciences Building, 745 Bannatyne Avenue, Winnipeg, MB, Canada R3E 0J9.

E-mail: kris@scrc.umanitoba.ca

Received 22 March 2016; revised 21 October 2016; accepted 29 October 2016; published online 20 December 2016 
loading, its high remodeling frequency makes it a potentially useful site for monitoring the effect of weight-bearing activities. Calcaneal $\mathrm{BMD}$ is higher in those participating in regular physical activity when compared with sedentary adults, ${ }^{15,16}$ and is increased after long-term marathon training. ${ }^{17}$ Thus, the calcaneus may be responsive to weightbearing exercise in adulthood, and may respond to loading after SCI. After SCI, the calcaneus demonstrates the greatest bone mineral loss compared with either the femur or the tibia. ${ }^{14}$ Precision analyses of DXA-based estimates of BMD in the calcaneus have only been carried out in the able-bodied population, with coefficient of variation (CV) values ranging between 1.3 and $2.8 \% .^{18-21}$

DXA has been used to demonstrate the rapid bone loss that occurs in the first years after SCI, and also the pattern of greater bone mineral loss in distal versus proximal leg bone regions. ${ }^{13,14,22}$ However, studies examining the reliability of repeated DXA-based scans at the knee have only recently begun to appear in the literature, carried out in persons with chronic SCI, ${ }^{23-25}$ able-bodied persons ${ }^{26}$ and with those in the acute stage of rapid bone mineral loss after SCI. ${ }^{25}$ Each of these reports acknowledges the need for further DXA-based measurement of BMD at these sites for independent validation, and none have included assessment of the calcaneus.

Precision errors in BMD of $3-8 \%$ have been attributed to differences in fat and soft tissue distribution when tested at the spine and hip in the general population. ${ }^{27-30}$ To date, precision analysis at the knee has not been carried out simultaneously in those with stable and expected normal body composition and bone density (able-bodied cohort) and in those with altered body composition and expected low BMD (chronic SCI cohort).

Therefore, our aim was to evaluate the precision of our DXA scanning protocol at the distal femur, proximal tibia and calcaneus in persons with expected normal body composition and BMD (able-bodied cohort) and in those with altered body composition caused by paralysis and low but stable BMD (persons with longstanding SCI), with each group meeting the precision assessment guidelines of the International Society for Clinical Densitometry. ${ }^{31}$

\section{MATERIALS AND METHODS}

\section{Participants}

Ten persons with motor-complete SCI of at least 2 years duration and 10 able-bodied persons were recruited to participate in the precision analysis (20 participants in total). The able-bodied cohort was not matched to the SCI cohort, and was recruited as a convenience sample, meant to reflect an average body composition and BMD. All participants were fracture free in the leg scanned, not pregnant, premenopausal and without a prior history of bone disease. The University of Manitoba Human Research Ethics Board approved the study protocol used, and all participants provided written informed consent. We certify that all applicable institutional and governmental regulations concerning the ethical use of human volunteers were followed during the course of this research.

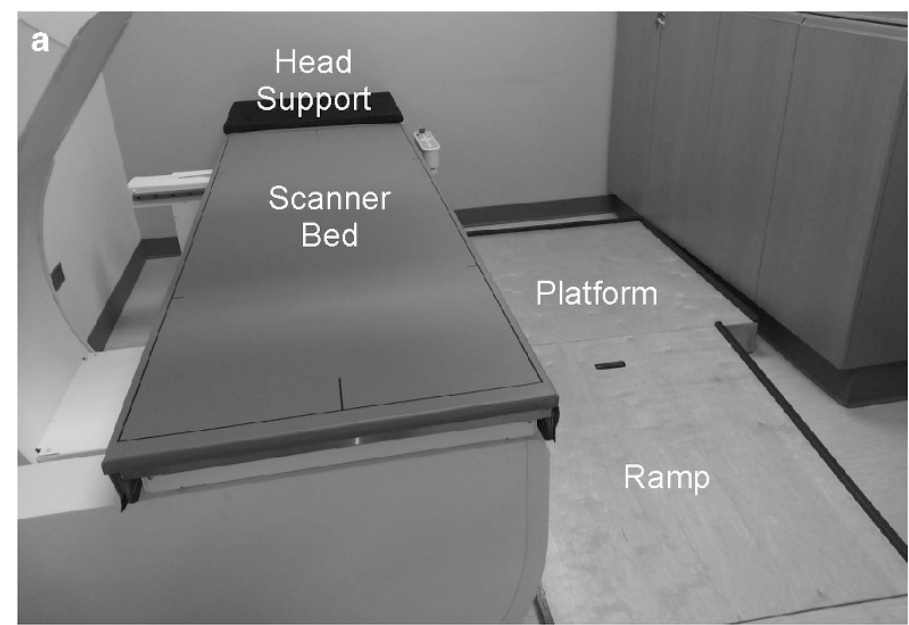

\begin{tabular}{|c|c|}
\hline b & $\begin{array}{c}\text { Length } \times \text { Width } \\
\text { x Height }(\mathrm{cm})\end{array}$ \\
\hline $\begin{array}{c}\text { Head } \\
\text { Support }\end{array}$ & $56 \times 71 \times 72$ \\
\hline $\begin{array}{c}\text { Scanner } \\
\text { Bed }\end{array}$ & $202 \times 70 \times 72$ \\
\hline Platform & $107 \times 107 \times 13$ \\
\hline Ramp & $107 \times 91 \times 13$ \\
\hline
\end{tabular}
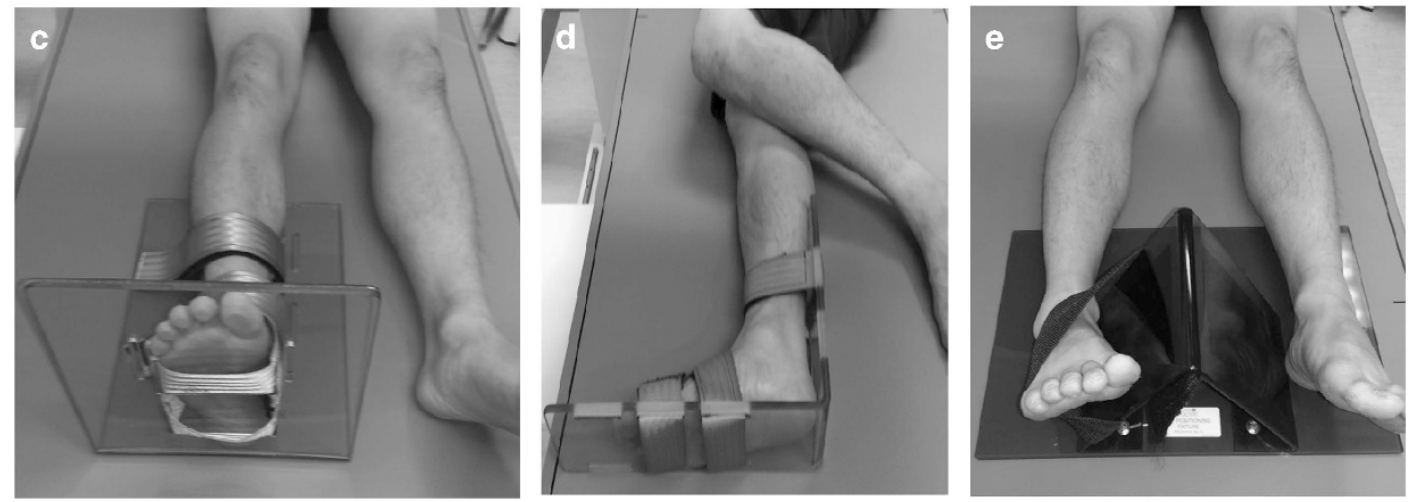

Figure 1 (a) Photograph of the scanner bed, head support, wheelchair ramp and platform used in the study. (b) Dimensions of the scanner bed and other items constructed to increase independent access to the scanner bed. The head support was constructed to provide additional length for the pediatric Hologic scanner bed as use of the forearm mode of the Hologic scanner software required the RI to be located $1 / 3$ of the bed length away from one edge of the scanner bed. (c) Support brace used for the knee scan in able-bodied participants. (d) Positioning and brace used for the heel scan for all study participants. (e) Positioning and brace used for participants with spinal cord injury to reduce the external rotation of the paralyzed leg during scanning. 

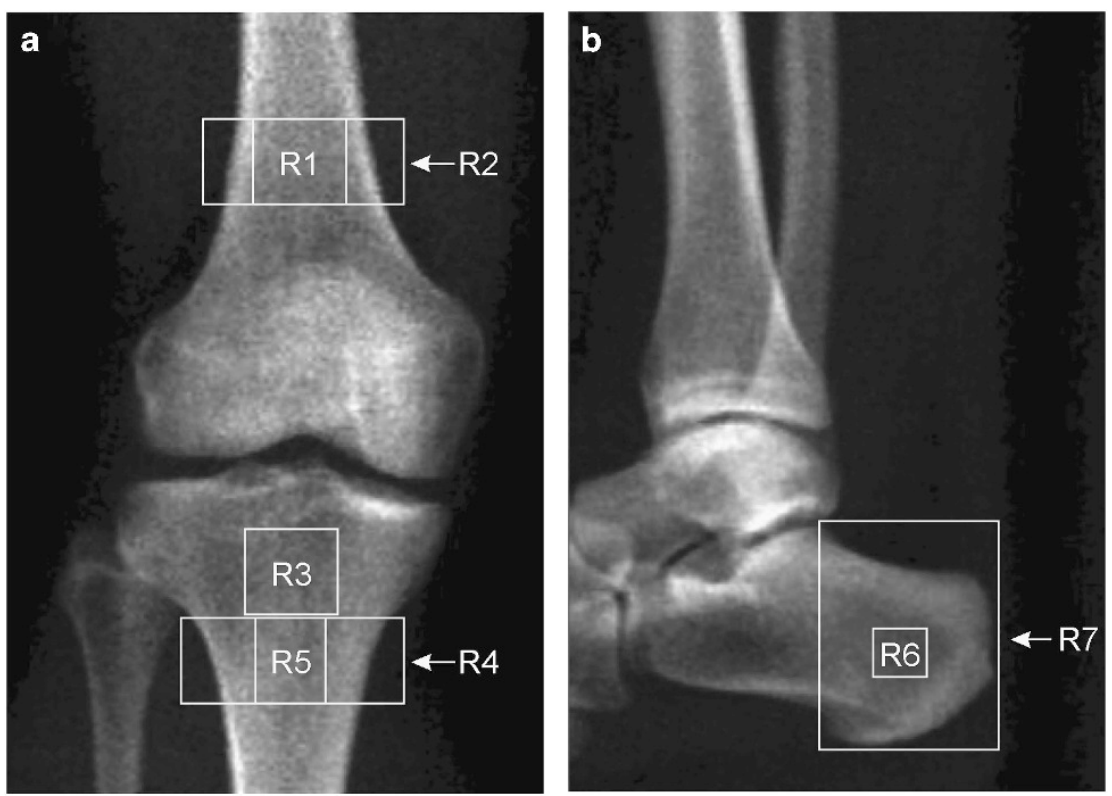

Figure 2 DXA scan image of the knee (a) and heel (b) from one of the study participants. The labeled boxes (R1-R7) delineate the seven RI that were used for the BMD measurements for this participant. The regions in the femur (R1, R2) correspond with the distal femoral metaphysis with the distal edge placed at $15 \%$, and the proximal edge placed at $20 \%$ of femur length, as measured from the terminus of the lateral femoral condyle. The width of R1 was set to $70 \%$ of the total femur width (measured at the midpoint of the medial and lateral sides of R1), and centered within the bone image. R3 was kept the same size as R1 and centered within the bone image. The proximal edges of R4 and R5 were visually identified and set at two pixels distal to the most distal point of contact visualized between the tibia and fibula. R4 spanned the medial and lateral bone borders and R5 was set to $50 \%$ of the bone width (also measured at the midpoint of the medial and lateral sides of R5) and centered within the bone image. (b) Two RIs were used in the calcaneus, including a region (R6) centered within the calcaneus posterior to the calcaneal tuberosity $\left(26 \times 12\right.$ pixels, $\left.1.32 \mathrm{~cm}^{2}\right)$ with the other encompassing the entire posterior calcaneal body (R7)

All participants with SCI had been assessed for level and extent of injury by manual strength testing in key muscle groups. ${ }^{32}$ Femur length was measured as the distance from the inguinal ligament (just distal to the palpated anterior superior iliac spine) to the proximal border of the patella, with the knee flexed at $90^{\circ}$ while seated. ${ }^{33}$

\section{Assessment of BMD by DXA}

The forearm mode of a Hologic QDR 4500A pediatric scanner (supplier: Hologic dual-energy $\mathrm{x}$-ray absorptiometry scanner; Hologic Inc., Bedford, MA, USA) was used to perform four knee and four heel scans by the same certified DXA technologist for each of the 20 participants. The choice for using the pediatric scanner was based on accessibility and convenience to the SCI Rehabilitation Hospital. The scanner is currently the only scanner available within our health region's SCI Rehabilitation Hospital complex, and as such, is the scanner most likely to be used in future intervention studies. As manufacturers are yet to develop acquisition algorithms for the knee or heel, the wrist acquisition module was used for scanning and analysis, as has been done in the previous studies examining precision of leg BMD in the SCI population. ${ }^{23,25}$ In accordance with the ISCD guidelines, each set of 10 participants were scanned four times and therefore each group met the minimum 30 degrees of freedom needed for statistical validity when calculating coefficients of variance for LSC. ${ }^{31,34}$ The four scans were completed for each participant on two visits separated by a mean of 9 days (range $=5-20$ days). During the study, mean CV in BMD measured daily in the L1-L4 spine phantom was $0.26 \%$, with the mean $\mathrm{CV}$ for individual vertebrae ranging from 0.45 to $0.65 \%$.

To improve accessibility and to increase the number of participants able to transfer without assistance or a lifting device, we had a ramp, platform and head support (Figure 1a) with dimensions shown in Figure 1b constructed. Although all our study participants were able to transfer independently with these room modifications, the addition of grab bars would improve accessibility. Further, although these room modifications would enable independent transfer by many SCI study participants, the use of a lifting device may still be required for those with more reduced motor function. We used a rotating scan order (knee, ankle, knee, ankle) at each visit to reduce the number of transfers while still allowing repositioning between successive scans. The able-bodied cohort completed the study in advance of those with SCI using a brace to stabilize the leg of interest while scanning the knee (Figure 1c) and heel (Figure 1d). Subsequent pilot testing of the brace in Figure 1c for knee scans in those with SCI demonstrated that the brace was insufficient for preventing external rotation of the paralyzed leg. Thus, we used a brace that could maintain greater internal rotation of each participant's paralyzed leg (Figure 1e) and achieve the bone orientation shown in Figure 2a, in which the overlap between tibia and fibula is minimized. Thus, knee scans were performed with the brace shown in Figure le in all participants with SCI.

Different size regions of interest (RIs) have been used in previous precision analyses of the bones around the knee, including RIs positioned within the visible bone borders, ${ }^{23}$ whereas others chose regions that spanned the entire bone width. ${ }^{25,26}$ Therefore, we assessed the precision of regions at the knee and heel that encompassed the external bone borders (R2, R4 and R7 in Figure 2) as well as regions contained within the visible bone borders (R1, R3, R5 and R6 in Figure 2). The size of each region was specific to each individual, and kept constant between scans. Consistent with earlier protocols ${ }^{23}$ and to reflect differences in anthropometric measures between participants, the length of all RIs in the femur and tibia was set to $5 \%$ of the femur length. In Figure $2 \mathrm{a}$, $\mathrm{R} 1$ and R2 correspond to the metaphysis of the distal femur, R3 to the proximal tibia epiphysis and R4 and R5 to the tibia metaphysis. For all scans, any automatically placed extraneous bone was manually removed from the interosseous membranes.

Precision studies of the calcaneus in able-bodied participants used either circumscribed RIs within the visible calcaneus bone borders ${ }^{18}$ or included most of the calcaneus bone. ${ }^{19,21,35}$ We therefore used both a smaller region centered within the calcaneus posterior to the calcaneal tuberosity (R6 in Figure 2b) and one containing the entire posterior calcaneal body (R7 in Figure 2b). 


\section{Precision calculations and statistics}

The average value, standard deviation (s.d.) and CV were calculated for each set of four BMD measurements at each RI. The root-mean-square coefficient of variation (RMS-CV) and root-mean-square standard deviation (RMS-s.d.) were calculated for each cohort of 10 participants. ${ }^{31}$ In particular, each participant's s.d. or CV was squared and then each set of 10 values summed and divided by 10 (total number in each cohort). The square root of each of these values was calculated to arrive at the RMS-s.d. or the RMS-CV for each cohort. The RMS-s.d. and RMS-CV, expressed either as $\mathrm{g} \mathrm{cm}^{-2}$ or \%, respectively, reflect the short-term precision for bone density at each RI. ${ }^{31}$ A statistical confidence level of $90 \%$ was used to calculate LSC (\%) for each RI. The LSC is the magnitude of measured change in BMD that needs to be surpassed during longitudinal examination of a given person in order for the change to be considered a real biological change, rather than a measurement fluctuation. ${ }^{31}$ Unpaired $t$-tests compared participant characteristics (height, age, body mass, body mass index and BMD). All data are presented as mean \pm s.d., and unless otherwise indicated, a $P$-value $<0.05$ was considered statistically significant. SPSS for Mac version 22 (IBM Corp., Armonk NY, USA) and GraphPad Prism 6.2 for Mac (GraphPad Software, La Jolla CA, USA) were used for statistical analysis.

\section{RESULTS}

\section{General}

The 10 participants with SCI included eight with tetraplegia (injury level: C6-L2; AIS (Abbreviated Injury Scale) classification: A-B; mean injury duration: $23 \pm 9$ years, range: 4-37 years).

Table 1 Calcaneus (R7) BMD values and calculated mean, s.d. and CV for each study participant

\begin{tabular}{|c|c|c|c|c|c|c|c|}
\hline \multirow{3}{*}{$\begin{array}{l}\text { Cohort/ } \\
\text { participant }\end{array}$} & \multicolumn{2}{|c|}{$B M D$ visit 1} & \multicolumn{2}{|c|}{$B M D$ visit 2} & \multirow{3}{*}{$\begin{array}{c}\text { Mean } \\
\left(\mathrm{g} \mathrm{cm}^{-2}\right)\end{array}$} & \multirow{3}{*}{$\begin{array}{c}\text { S.d. } \\
\left(g c m^{-2}\right)\end{array}$} & \multirow{3}{*}{$\begin{array}{l}C V \\
\text { (\%) }\end{array}$} \\
\hline & Scan & Scan & Scan & Scan & & & \\
\hline & 1 & 2 & 3 & 4 & & & \\
\hline
\end{tabular}

$A B$
1
2
3
4
5
6
7
8
9

1
2
3
4
5
6
7
8
9
10

$\begin{array}{llll}0.784 & 0.780 & 0.781 & 0.783 \\ 0.655 & 0.642 & 0.648 & 0.641 \\ 1.031 & 1.023 & 0.987 & 1.031 \\ 0.724 & 0.721 & 0.746 & 0.733 \\ 0.767 & 0.786 & 0.781 & 0.777 \\ 0.849 & 0.824 & 0.827 & 0.828 \\ 0.753 & 0.745 & 0.747 & 0.729 \\ 0.670 & 0.679 & 0.648 & 0.684 \\ 0.689 & 0.743 & 0.708 & 0.701 \\ 0.864 & 0.879 & 0.861 & 0.905\end{array}$

0.782

0.646

1.018

0.731

0.778

0.832

0.744

0.670

0.710

0.877

0.779

$S C l$
11
12
13
14
15
16
17
18
19
20

Cohort mean:

$\begin{array}{lllllll}0.367 & 0.364 & 0.374 & 0.366 & 0.368 & 0.004 & 1.2 \\ 0.348 & 0.343 & 0.351 & 0.349 & 0.348 & 0.003 & 1.0 \\ 0.289 & 0.296 & 0.302 & 0.315 & 0.301 & 0.007 & 2.2 \\ 0.441 & 0.434 & 0.441 & 0.435 & 0.438 & 0.004 & 0.9 \\ 0.273 & 0.266 & 0.319 & 0.318 & 0.294 & 0.028 & 9.7 \\ 0.201 & 0.207 & 0.202 & 0.209 & 0.205 & 0.004 & 1.9 \\ 0.250 & 0.251 & 0.243 & 0.248 & 0.251 & 0.003 & 1.2 \\ 0.301 & 0.290 & 0.281 & 0.290 & 0.291 & 0.008 & 2.8 \\ 0.339 & 0.345 & 0.324 & 0.331 & 0.335 & 0.009 & 2.7 \\ 0.235 & 0.238 & 0.236 & 0.237 & 0.237 & 0.001 & 0.5 \\ & & & & 0.306 & & \end{array}$

Abbreviations: $\mathrm{BMD}$, bone mineral density; $\mathrm{CV}$, coefficient of variation; $\mathrm{R} 7$, region of interest; s.d., standard deviation.

BMD $\left(\mathrm{g} \mathrm{cm}^{-2}\right)$ values for the calcaneus (R7). Each participant's mean BMD value, s.d. $\left(\mathrm{g} \mathrm{cm}^{-2}\right)$ and $\mathrm{CV}(\%)$, as well as each cohort's mean BMD, s.d. and CV are shown.
Participants with SCI were older (mean: 44 years, range: 23-58, median: 47) than the reference able-bodied cohort (mean age: 29 years, range: $21-48$, median: $28, P<0.01$ ), but were otherwise similar in height ( $177 \pm 9 \mathrm{~cm}$ versus $171 \pm 10 \mathrm{~cm}$ for the $\mathrm{AB}$ cohort) and body mass index $\left(25.1 \pm 4.8 \mathrm{~kg} \mathrm{~m}^{-2}\right.$ versus $24.7 \pm 3.4 \mathrm{~kg} \mathrm{~m}^{-2}$ in the $\mathrm{AB}$ cohort). Table 1 presents all BMD values measured for the entire calcaneus, R7. BMD in the SCI cohort was significantly decreased at each region compared with the $\mathrm{AB}$ cohort, ranging from $33 \%$ (calcaneus) to $56 \%$ (tibia) of the mean BMD measured in the ablebodied cohort (Figure 3; all $P<0.001$ ). Mean BMD, confidence intervals and precision values for each region are listed in Table 2.

\section{Precision error and LSC}

Short-term precision values (RMS-CV, \%) calculated for each region of interest for both cohorts ranged from relatively low values at the calcaneus (under $4 \%$ ) and tibia (under 5\%) to higher values $10.2 \%$ (SCI cohort; $4.8 \%$ in $\mathrm{AB}$ cohort) at the femur (Table 2). Overall, precision was greatest in the calcaneus and least in the femur. For each bone area, the use of larger RI, encompassing the bone borders, required less time to calculate BMD. Also, Table 2 shows that the precision values calculated at larger RI were slightly lower compared with those calculated using the smaller RI (compare RMS-CV values at the small RI (R1, R3, R5 and R6) with values at the larger RI (R2, R4 and R7)). Using a $90 \%$ level of statistical confidence, the LSC ranged from $4.3 \%$ to $11.3 \%$ in the $\mathrm{AB}$ cohort and from $8.1 \%$ to $12.9 \%$ in the SCI cohort for regions R2 to R7. R1 had the highest LSC, at $23.8 \%$ in the SCI cohort and $13.4 \%$ for the $\mathrm{AB}$ cohort.

\section{DISCUSSION}

Our findings indicate that precision estimates in those with stable and normal leg BMD and soft tissue distribution (able-bodied cohort) were generally similar to values determined for those with stable low $\mathrm{BMD}$ and severe muscle atrophy (SCI cohort). Precision values were also similar, albeit slightly lower, at larger RIs that encompassed the bone borders. This study is the first to describe the precision for DXAbased BMD measurement of the calcaneus after SCI, and demonstrates that precision at the heel is similar (or slightly better) compared with either the distal femur or proximal tibia. Finally, we provide values for the least significant DXA-based BMD change (LSC) that should be exceeded to suggest that true biological change has occurred in the

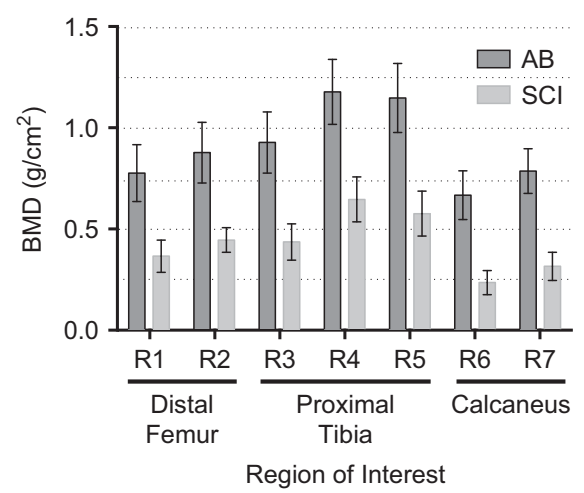

Figure 3 Mean BMD $\left(\mathrm{g} \mathrm{cm}^{-2}\right.$ ) in participants with longstanding $\mathrm{SCl}$ (light gray) and in the reference able-bodied persons with expected normal bone density (dark gray, $A B$ ) for each of the seven RIs measured in the distal femur (R1 and R2), proximal tibia (R3-R5) and calcaneus (R6, R7). Bars show s.d. from each group's mean for each region, and mean BMD was significantly lower at each region (all unpaired $t$-test $P$-values $<0.0001$ ). 
Table 2 Mean BMD and precision values for each region at the knee and heel in the $\mathrm{AB}$ and $\mathrm{SCl}$ cohorts

\begin{tabular}{|c|c|c|c|c|c|}
\hline Region & Cohort & $\begin{array}{c}\text { Mean BMD } \\
\left(\mathrm{g} \mathrm{cm}^{-2}\right)\end{array}$ & $\begin{array}{l}\text { RMS-s.d. } \\
\left(\mathrm{g} \mathrm{cm}^{-2}\right)\end{array}$ & $\begin{array}{c}R M S-C V \\
(\%)\end{array}$ & $\begin{array}{l}\angle S C \\
(\%)\end{array}$ \\
\hline R1 & $A B$ & 0.77 & 0.042 & 5.73 & 13.4 \\
\hline $\begin{array}{l}\text { Distal femur } \\
\text { Metaphysis } \\
\text { Small region }\end{array}$ & $\mathrm{SCl}$ & 0.36 & 0.030 & 10.20 & 23.8 \\
\hline R2 & $A B$ & 0.87 & 0.043 & 4.83 & 11.3 \\
\hline $\begin{array}{l}\text { Distal femur } \\
\text { Metaphysis } \\
\text { Large region }\end{array}$ & $\mathrm{SCl}$ & 0.44 & 0.023 & 5.55 & 12.9 \\
\hline R3 & $A B$ & 0.92 & 0.038 & 4.07 & 9.5 \\
\hline $\begin{array}{l}\text { Proximal tibia } \\
\text { Epiphysis } \\
\text { Small region }\end{array}$ & $\mathrm{SCl}$ & 0.43 & 0.021 & 4.30 & 10.0 \\
\hline R4 & $A B$ & 1.17 & 0.045 & 3.81 & 8.9 \\
\hline $\begin{array}{l}\text { Proximal tibia } \\
\text { Metaphysis } \\
\text { Large region }\end{array}$ & $\mathrm{SCl}$ & 0.64 & 0.022 & 3.47 & 8.1 \\
\hline R5 & $A B$ & 1.14 & 0.051 & 4.64 & 10.8 \\
\hline $\begin{array}{l}\text { Proximal tibia } \\
\text { Metaphysis } \\
\text { Small region }\end{array}$ & $\mathrm{SCl}$ & 0.57 & 0.030 & 5.02 & 11.7 \\
\hline R6 & $A B$ & 0.66 & 0.022 & 3.31 & 7.7 \\
\hline $\begin{array}{l}\text { Calcaneus } \\
\text { Small region }\end{array}$ & $\mathrm{SCl}$ & 0.23 & 0.012 & 4.91 & 11.5 \\
\hline R7 & $A B$ & 0.78 & 0.015 & 1.85 & 4.3 \\
\hline $\begin{array}{l}\text { Calcaneus } \\
\text { Large region }\end{array}$ & $\mathrm{SCl}$ & 0.31 & 0.011 & 3.63 & 8.5 \\
\hline
\end{tabular}

Abbreviations: $A B$, able-bodied; BMD, bone mineral density; LSC, least significant change; RMS-CV, root-mean-square coefficient of variation; RMS-s.d., root-mean-square standard deviation; $\mathrm{SCl}$, spinal cord injured.

Mean BMD $\left(\mathrm{g} \mathrm{cm}^{-2}\right)$, short-term (RMS-SD $\left(\mathrm{g} \mathrm{cm}^{-2}\right)$; RMS-CV $\left.\left(\mathrm{g} \mathrm{cm}^{-2}\right)\right)$ and long-term precision (LSC (\%)) values calculated for each region of interest (RI, R1-R7) and each cohort (AB, $\mathrm{SCl})$.

Italic entries signify numbers from the $\mathrm{SCl}$ cohort.

distal femur, proximal tibia and at the calcaneus in those with SCI. Given that there are no currently accepted standards for precision of DXA-based BMD measurement at sites of relevance to those with SCI, this study provides useful information for studies examining the effect of interventions to reduce bone mineral loss after SCI.

Our estimates of short-term precision at the knee are generally consistent with the few studies that have assessed precision in the femur and tibia. In particular, we calculated a short-term precision value of $4.3 \%$ (RMS-CV) for R3 in the proximal tibia, similar to the $5.9 \%$ determined by Morse et al. ${ }^{23}$ Our calculation of $5.55 \%$ at R2 in the distal femur is similar to the two precision values $(3.86 \%, 5.53 \%)$ calculated for a similar region by McPherson et al. ${ }^{25}$ in those with chronic SCI. In terms of comparisons with our $\mathrm{AB}$ cohort, Bakkum et al. ${ }^{26}$ reported the smallest detectable difference to range from $0.077 \mathrm{~g} \mathrm{~cm}^{-2}$ in the distal femur to $0.047 \mathrm{~g} \mathrm{~cm}^{-2}$ in the proximal tibia in participants with normal BMD. ${ }^{26}$ These values are consistent with our corresponding values in the distal femur $\left(0.042 \mathrm{~g} \mathrm{~cm}^{-2}\right.$ at $\mathrm{R} 1$ and $0.043 \mathrm{~g} \mathrm{~cm}^{-2}$ at R2) and proximal tibia $\left(0.038 \mathrm{~g} \mathrm{~cm}^{-2}\right.$ at $\left.\mathrm{R} 3\right)$ from our $\mathrm{AB}$ cohort.

Calcaneus BMD in our SCI cohort $\left(0.31 \mathrm{~g} \mathrm{~cm}^{-2}\right.$ (R7)) was similar to the $0.32 \mathrm{~g} \mathrm{~cm}^{-2}$ measured at least 1 year after SCI by Garland et al. ${ }^{14}$ In terms of BMD and precision in the general population, Sievanen et al. ${ }^{21}$ found calcaneus BMD to be $0.671 \mathrm{~g} \mathrm{~cm}^{-2}$ (precision $=1.3 \%)$, consistent with $0.78 \mathrm{~g} \mathrm{~cm}^{-2}$ (precision $=1.85 \%$ ) we observed in our $\mathrm{AB}$ cohort at R7 (Table 1). Given slightly better precision of BMD measured at the heel compared with other leg RIs, incorporation of this site in assessing leg BMD will provide an additional site, and possibly an earlier time-point, for monitoring treatment effect. The calcaneus could be used instead of other sites, depending on the degree and type of leg contractures present in study participants with SCI. Additionally, changes in bone mineral content because of activity-dependent interventions that might preferentially affect the heel (e.g., passive standing) could be assessed.

The precision of monitoring BMD at small, circumscribed RIs (R1, R3, R5 and R6) compared with larger regions encompassing the entire bone borders (R2, R4 and R7) throughout the leg was relatively similar. However, given that fewer calculations and fewer anthropometric measures (e.g., bone width) are needed when using larger RIs compared with identifying smaller regions located within cortical bone borders, we suggest using larger RIs, as described here and previously ${ }^{25}$ for treatment studies.

Our least precise site for assessing BMD, R1 in the distal femur, at $10.2 \%$, was higher than the $3.01 \%$ reported for a similar region by Morse et al..$^{23}$ A limitation of our study is that it is unclear why our value at this site is inconsistent with this previous report, and is larger than that in the other sites we examined within the leg, given that error introduced during positioning and repositioning should similarly affect precision throughout the limb in our study, or at least affect both sites within the femur equally. However, given the relatively small size of R1, it is possible that changes in orientation of the knee may adversely affect precision at this site more than at the larger region R2 (encompassing the bone borders) that we also examined. In future studies, it would be of interest to examine whether using even larger RIs at the knee can provide more precision in bone density measurement.

Our sample sizes adhered to the recommendations of the ISCD for determining short- and long-term precision. ${ }^{31,34}$ However, Leslie et al. ${ }^{36}$ showed that although the calculated LSC values from different subsets of 30 participants were not significantly different than the value calculated from the entire sample ( $>190$ participants), the use of LSCs calculated from these different subsets of participants caused variability in whether a given individual was categorized as having a BMD change greater or less than the LSC. LSC values are intended to reflect the minimum change in BMD that needs to be surpassed before suggesting that a given individual has shown true biological change. ${ }^{11}$

The precision of DXA-based BMD assessments can be increased by incorporating the use of multiple baseline, and follow-up scans change during intervention studies. For example, using two, rather than a single, DXA-based scan to measure BMD at baseline and follow-up reduces the LSC value by $30 \%$ for any level of statistical confidence. ${ }^{31}$

As noted above, our LSC values are generally consistent with earlier studies of the knee for both our AB and SCI cohorts. However, the LSC values reported here and elsewhere ${ }^{23,26}$ are greater than the precision values calculated for the general population at the spine $(\mathrm{LSC}=5.3 \%)$ and proximal femur $(\mathrm{LSC}=6.9 \%) .{ }^{12}$ Given that precision values at the hip and spine rely on stringent rules regarding acceptable leg positioning, it suggests that those working with SCI will 
need to accept LSC values of $>10 \%$ for any given RI, in the absence of developing precise guidelines regarding acceptable positioning of the leg during DXA-based assessments of BMD at the knee and heel. Of interest to this point is the observation that studies demonstrating statistically significant change in BMD during intervention studies after SCI required average changes of $10 \%,{ }^{7,10}$ consistent with the LSC values reported here.

\section{CONCLUSION}

Changes in BMD $>10 \%$ are needed to suggest that any intervention is leading to true biological change (versus being a DXA-based measurement error) at sites of interest after SCI. The heel is presented as an additional site for monitoring bone mineral changes after SCI with precision errors similar to the more commonly scanned sites in the tibia and femur. Strict guidelines regarding the acceptable positioning of the legs after SCI are needed to reduce precision error in future studies. In the meantime, incorporating the use of multiple scans at baseline and follow-up should reduce precision error.

\section{DATA ARCHIVIENG}

There were no data to deposit.

\section{CONFLICT OF INTEREST}

The authors declare no conflict of interest.

\section{ACKNOWLEDGEMENTS}

Funding for this project was provided from the University of Manitoba Research Grants Program, the Will to Win Gifted Professorship (to KC), the Daremax Foundation (to WP) and the Canadian Institutes of Health Research (to WP) and the University of Manitoba Undergraduate Research Award (to WJK). We thank the participants for volunteering their time and Christopher MacDonell (PhD) for critical comments and review of this manuscript.

1 Qin W, Bauman WA, Cardozo C. Bone and muscle loss after spinal cord injury: organ interactions. Ann NY Acad Sci 2010; 1211: 66-84.

2 Biering-Sorensen F, Hansen B, Lee BS. Non-pharmacological treatment and prevention of bone loss after spinal cord injury: a systematic review. Spinal Cord. 2009; 47: 508-518

3 Vestergaard P, Krogh K, Rejnmark L, Mosekilde L. Fracture rates and risk factors for fractures in patients with spinal cord injury. Spinal Cord 1998; 36: 790-796.

4 Logan WC Jr, Sloane R, Lyles KW, Goldstein B, Hoenig HM. Incidence of fractures in a cohort of veterans with chronic multiple sclerosis or traumatic spinal cord injury. Arch Phys Med Rehabil 2008; 89: 237-243.

5 Lazo MG, Shirazi P, Sam M, Giobbie-Hurder A, Blacconiere MJ, Muppidi M. Osteoporosis and risk of fracture in men with spinal cord injury. Spinal Cord 2001; 39: 208-214.

6 Gifre L, Vidal J, Carrasco J, Portell E, Puig J, Monegal A et al. Incidence of skeletal fractures after traumatic spinal cord injury: a 10-year follow-up study. Clin Rehabil 2014; 28: 361-369.

7 Mohr T, Podenphant J, Biering-Sorensen F, Galbo H, Thamsborg G, Kjaer M. Increased bone mineral density after prolonged electrically induced cycle training of paralyzed limbs in spinal cord injured man. Calcif Tissue Int 1997; 61: 22-25.

8 Dudley-Javoroski S, Saha PK, Liang G, Li C, Gao Z, Shields RK. High dose compressive loads attenuate bone mineral loss in humans with spinal cord injury. Osteoporos Int 2012; 23: 2335-2346.

9 de Bruin ED, Frey-Rindova P, Herzog RE, Dietz V, Dambacher MA, Stussi E. Changes of tibia bone properties after spinal cord injury: effects of early intervention. Arch Phys Med Rehabil 1999; 80: 214-220.

10 Alekna V, Tamulaitiene M, Sinevicius $T$, Juocevicius A. Effect of weight-bearing activities on bone mineral density in spinal cord injured patients during the period of the first two years. Spinal Cord 2008; 46: 727-732.
11 Bonnick SL. Bone Densitometry in Clincal Practice: Application and Interpretation, 3rd edn. Humana Press, Springer: New York, NY, 2010.

12 Schousboe JT, Shepherd JA, Bilezikian JP, Baim S. Executive summary of the 2013 International Society for Clinical Densitometry Position Development Conference on bone densitometry. J Clin Densitom 2013; 16: 455-466.

13 Biering-Sorensen $\mathrm{F}$, Bohr H, Schaadt O. Bone mineral content of the lumbar spine and lower extremities years after spinal cord lesion. Paraplegia 1988; 26: 293-301.

14 Garland DE, Adkins RH, Scott M, Singh H, Massih M, Stewart C. Bone loss at the os calcis compared with bone loss at the knee in individuals with spinal cord injury. J Spinal Cord Med 2004; 27: 207-211.

15 Suominen H, Heikkinen E, Vainio P, Lahtinen T. Mineral density of calcaneus in men at different ages: a population study with special reference to life-style factors. Age Ageing 1984; 13: 273-281.

16 Pettersson U, Nilsson M, Sundh V, Mellstrom D, Lorentzon M. Physical activity is the strongest predictor of calcaneal peak bone mass in young Swedish men. Osteoporos Int 2010; 21: 447-455.

17 Williams JA, Wagner J, Wasnich R, Heilbrun L. The effect of long-distance running upon appendicular bone mineral content. Med Sci Sports Exerc 1984; 16: 223-227.

18 Szucs J, Jonson R, Granhed H, Hansson T. Accuracy, precision, and homogeneity effects in the determination of the bone mineral content with dual photon absorptiometry in the heel bone. Bone 1992; 13: 179-183.

19 Yamada M, Ito M, Hayashi K, Nakamura T. Calcaneus as a site for assessment of bone mineral density: evaluation in cadavers and healthy volunteers. Am J Roentgenol 1993; 161: 621-627.

20 Pacheco EM, Harrison EJ, Ward KA, Lunt M, Adams JE. Detection of osteoporosis by dual energy X-ray absorptiometry (DXA) of the calcaneus: is the WHO criterion applicable? Calcif Tissue Int 2002; 70: 475-482.

21 Sievanen H, Oja P, Vuori I. Precision of dual-energy x-ray absorptiometry in determining bone mineral density and content of various skeletal sites. J Nucl Med 1992; 33: 1137-1142.

22 Dauty M, Perrouin Verbe B, Maugars Y, Dubois C, Mathe JF. Supralesional and sublesional bone mineral density in spinal cord-injured patients. Bone 2000; 27 : 305-309.

23 Morse LR, Lazzari AA, Battaglino R, Stolzmann KL, Matthess KR, Gagnon DR et al. Dual energy $x$-ray absorptiometry of the distal femur may be more reliable than the proximal tibia in spinal cord injury. Arch Phys Med Rehabil 2009; 90 : 827-831.

24 Haddaway MJ, Davie MW, Davies HL, Sharp CA. Application of sub-regional analysis to bone mineral density of the lower limb from whole body DXA scans. Physiol Meas 2013; 34: 757-768.

25 McPherson JG, Edwards WB, Prasad A, Troy KL, Griffith JW, Schnitzer TJ. Dual energy X-ray absorptiometry of the knee in spinal cord injury: methodology and correlation with quantitative computed tomography. Spinal Cord 2014; 52: 821-825.

26 Bakkum AJ, Janssen TW, Rolf MP, Roos JC, Burcksen J, Knol DL et al. A reliable method for measuring proximal tibia and distal femur bone mineral density using dualenergy X-ray absorptiometry. Med Eng Phys 2014; 36: 387-390.

27 Yu EW, Thomas BJ, Brown JK, Finkelstein JS. Simulated increases in body fat and errors in bone mineral density measurements by DXA and QCT. J Bone Miner Res 2012; 27: 119-124.

28 Tothill P, Weir N, Loveland J. Errors in dual-energy X-ray scanning of the hip because of nonuniform fat distribution. J Clin Densitom 2014; 17: 91-96.

29 Tothill $\mathrm{P}$, Avenell A. Errors in dual-energy X-ray absorptiometry of the lumbar spine owing to fat distribution and soft tissue thickness during weight change. $\mathrm{Br} J$ Radiol 1994; 67: 71-75.

30 Farrell TJ, Webber CE. The error due to fat inhomogeneity in lumbar spine bone mineral measurements. Clin Phys Physiol Measure 1989; 10: 57-64.

31 Bonnick SL, Johnston CC Jr, Kleerekoper M, Lindsay R, Miller P, Sherwood L et al. Importance of precision in bone density measurements. J Clin Densitom 2001; 4: $105-110$.

32 Kendall FP, Kendall McCreary E, Provance PG, Rodgers M, Romani W. Muscles: Testing and Function, with Posture and Pain, 5th edn. Lippincott Williams and Wilkins, Baltimore, MD, USA, 2005, 560pp.

33 Lohmann TG, Roche AF, Martorell R. Anthropometric Standardization Reference Manual. Human Kinetics Books: Champaign, IL, USA, 1988, 177pp.

34 Baim S, Wilson CR, Lewiecki EM, Luckey MM, Downs RW Jr, Lentle BC. Precision assessment and radiation safety for dual-energy X-ray absorptiometry: position paper of the International Society for Clinical Densitometry. J Clin Densitom 2005; 8: $371-378$.

35 Ito M, Nishida A, Kono J, Kono M, Uetani M, Hayashi K. Which bone densitometry and which skeletal site are clinically useful for monitoring bone mass? Osteoporos Int 2003; 14: 959-964.

36 Leslie WD, Moayyeri A. Minimum sample size requirements for bone density precision assessment produce inconsistency in clinical monitoring. Osteoporos Int 2006; 17: 1673-1680. 